concern for learning how to cope with the immutable issues of inequality. The authors all examine the contention that equality should be the primary objective of the health service. The common theme is that there are no ready-made criteria for acceptable and unacceptable inequalities. All of the essays suggest that the issues of inequality should be approached in an incremental, pragmatic fashion, and dealt with when and if society becomes concerned about them. Rudolf Klein and Peter Collison present the difficulties of establishing which inequalities are important. Given that there are differences in health status caused by biological or social differences, what quantities of resources should be brought to bear to reduce these differences? A J Culyer considers the issues raised by the assertion that we are born with unequal chances of good health (however defined), and examines alternative methods for allocating resources. Robert Pinker puts forward a convincing case for the promotion of consumer choice, through a mixture of public and private health systems, given that all inequalities are inerradicable. Taken together, the arguments of the four professors suggest that theoretical concerns about equality are not relevant to the present making of health policy. There is much that can be done without having to revert to the need for clearly defined social welfare functions in health-policy making.

Now that the NHS is settling down to its new management philosophy, it is time to return to the policy questions and to address them in the context of the general management. Acceptable Inequalities is a useful beginning for the much needed new thinking in this area.

ELLIE SCRIVENS Lecturer in Public Sector Management London Business School Sussex Place, Regents Park London NWI 4SA

\section{Stress:}

\section{The Challenge to Christian caring}

Gaius Davies, 287 pages, Eastbourne, £6.95, Kingsway, 1988

The author of this book is a consultant psychiatrist at a London (teaching) hospital and a practising Christian. His book is primarily addressed to a lay readership and addresses the belief held

by some Christians that if you have a faith in God then you should be immune to the effects of stress and have no need of help from drugs or professional carers. In arguing against this position Davies shows the need for a true partnership between a supportive Christian community and those who offer professional help via the accurate diagnosis and appropriate treatment of physical and psychological problems.

Whilst this book does not fall naturally into the category of 'ethics' nevertheless it does, by implication, underline the importance of autonomy, partnership and respect of the individual and his/her personal value system. Failure to recognise the patient's basic premise regarding 'Godgiven' immunity from stress can result in the person feeling guilty and sinful for having fallen from what some would regard as expected Christian behaviour.

Davies illustrates well that the wholeperson approach is not only a reminder to clinicians and others to respect the spiritual aspect of the person but is also a prompt to the community of faith not to ignore the body and mind and the care available in good clinical practice. The various chapters in this book cover a wide variety of forms of stress ranging through loss, sadness, personality problems, conscience, sex and old age to a variety of forms of mental illness and 'breakdown'.

This book will be of interest to those who offer pastoral care within a Christian context and argues very persuasively for a healthy partnership and the right use and assessment of what help can be offered both spiritually and medically. There is much helpful advice for those seeking to distinguish between expressions of spirituality and those requiring clinical diagnosis and treatment: as in the case of exorcism or conversion phenomena.

PETER W SPECK Chaplain Royal Free Hospital London

\title{
The Physician as Captain of the Ship
}

\section{N M P King, L R Churchill and A W Cross, 254 pages, Dordrecht, $£ 44.00$, D Reidel, 1988}

This book is a collection of twelve thoughtful essays, chiefly by authors from American departments of social medicine or ethics. They discuss the current uneasy relationship between doctors and their patients on the one hand, and nurses, paramedical staff anç administrators on the other. They all: agree that changes are occurring, and that doctors must ensure that these changes are not detrimental to health care. Thus for instance, some American hospital administrators press doctors to maximise the income for a hospital bye concentrating on profitable medicine Doctors are urged everywhere in thisbook to become involved in the decisions of administrators, or to take $\overrightarrow{-}$ on administrative roles themselves.

These delicate subjects are apposite to today's problems here in the Nationa范 Health Service, for we also are being encouraged to become hospitatu managers and budget holders, toexamine the costs of what we are doing and to take part in vigorous clinicab audit. These influences are a reflection. of changes in society, and so doctors, wes are told, must change or be changed. OAD until, as one essayist describes it in the्ष nautical metaphor running through this book, 'the physician's grip is wrested from the tiller and chained to the oars'. In an essay on the changing rolecofo nurses in hospitals, it is pointed out totat before 1900 doctors were not mus involved in the running of hospitas. which was then the duty of boards of trustees. Only when more patients were admitted to hospitals for surgicab procedures did the doctors seek tळ influence hospital management and spending.

The other area extensively discussed is the relationship between doctors as 'captains' and other professional staff chiefly nurses, in the management of the patient. The specialised skills of nurses in particular have vastly increased, and no longer do the consider themselves the Nightingaliar hand-maidens. They and other staff are pressing to be involved in decision? regarding the management of patients All the essayists agree that doctors are likely to remain, if not captains, them. the leaders, but the nature of theion future role is uncertain.

I wonder, however, whether the physician is better portrayed as a pilotw and the captain as the patient, askingo receiving and usually accepting the advice from the pilot. Only once did $F^{\circ}$ find a mention of the fundamental? personal relationship between the patient and his doctor, to whom h్5 comes for advice, and subsequently for help. He expects the doctors to suggesf safe treatment and to protect him, fo instance, against administrators wh $\bar{Q}$ perhaps may want to accelerate his 